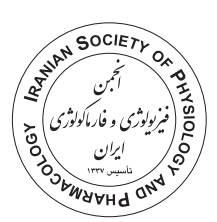

\title{
Silymarin reduced cisplatin-induced hyperalgesia by suppressing oxidative stress in male rats
}

\author{
Alireza Mohajjel Nayebi ${ }^{1,2^{*}}$ (iD, Ali Hashemian², Hassan Rezazadeh ${ }^{1,2}$, Mohammad Charkhpour², Kiarash Fekri²,3, \\ Rasool Haddadi ${ }^{4}$
}

1. Drug Applied Research Center, Tabriz University of Medical Sciences, Tabriz, Iran

2. Department of Pharmacology and Toxicology, Faculty of Pharmacy, Tabriz University of Medical Sciences, Tabriz, Iran

3. Neurosciences Research Center, Tabriz University of Medical Sciences, Tabriz, Iran

4. Department of Pharmacology and Toxicology, Faculty of Pharmacy, Hamadan University of Medical Sciences, Hamadan, Iran

\section{ABSTRACT}

Introduction: Cisplatin is an antineoplastic agent which is used in treatment of various cancers. However its clinical use is associated with oxidative stress-mediated neuropathic pain. This research aimed to explore the effect of silymarin on cisplatin-induced hyperalgesia $(\mathrm{CIH})$ and oxidative stress biomarkers in male rats.

Methods: Fifty-six male rats were allocated into seven equal groups. Hyperalgesia was caused by intraperitoneal single dose administration of cisplatin $(1 \mathrm{mg} / \mathrm{kg})$ and assessed by utilizing tail-flick method. The impact of silymarin $(25,50$ and $100 \mathrm{mg} / \mathrm{kg} /$ day for 15 days) on CIH was investigated on days 1, 5, 10 and 15. Blood samples were collected to assess malondialdehyde (MDA), glutathione peroxidase (GPx), superoxide dismutase (SOD) and total antioxidant status (TAS) on day fifteen.

Results: Single dose injection of cisplatin $(1 \mathrm{mg} / \mathrm{kg})$ could cause a significant hyperalgesia on days 5,10 and 15 . CIH was abolished by daily administration of silymarin $(50$ and $100 \mathrm{mg} /$ $\mathrm{kg}$ ) on days 10 and 15 . Serum MDA level was decreased in cisplatin and silymarin (100 mg/ $\mathrm{kg}$ ) co-treated rats, while there was an increase in GPx, SOD as well as TAS parameters.

Conclusion: The results of this study revealed that silymarin prevents from $\mathrm{CIH}$ possibly by improving lipid peroxidation and oxidative stress biomarkers. Other clinical studies should be performed to establish possible use of silymarin for treatment of $\mathrm{CIH}$ in susceptible individuals.

\section{Introduction}

Cisplatin is an effective cytotoxic drug used for the treatment of various cancers including ovarian, testicular and bladder cancers. Its cytotoxic effect is performed by cross-linking DNA and blocking its duplication in cancer cells (Lee et al., 2015). Its clinical use is associated with neuropathic pain as a major dose limiting side effect

\author{
Keywords: \\ Cisplatin \\ Silymarin \\ Hyperalgesia \\ Oxidative stress
}

(Khasabova et al., 2019). Several studies have proved the oxidative stress-mediated neurotoxicity of cisplatin which can lead to neuropathy and hyperalgesia. In these studies, neuronal drug transporters (Cavaletti et al., 2014), platinum DNA adducts (Dzagnidze et al., 2007; Ta et al., 2006), interference with cell cycle and mitochondrial dysfunctions (Gill and Windebank, 1998;

\footnotetext{
* Corresponding author: Alireza Mohajjel Nayebi, nayebia@tbzmed.ac.ir

Received 23 July 2020; Revised from 31 October 2020; Accepted 14 November 2020
}

Citation: Mohajjel Nayebi A, Hashemian A, Rezazadeh H, Charkhpour M, Fekri K, Haddadi R. Silymarin reduced cisplatin-induced hyperalgesia by suppressing oxidative stress in male rats. Physiology and Pharmacology 2021; 25: 146-153.http://dx.doi.org/10.32598/ppj.25.2.60 
Lomeli et al., 2017; Podratz et al., 2011), inhibition of transcription (Todd and Lippard, 2009), altering the activity of voltage-dependent anion channel proteins (Yang et al., 2006) and oxidative stress (Areti et al., 2014; Kim et al., 2010) were found to be involved in neurotoxicity process of cisplatin. Oxidative stressmediated neurotoxicity is one of the prominent proposed mechanisms for cisplatin-induced hyperalgesia (CIH). Studies show that cisplatin results in mitochondrial dysfunction by inhibiting mitochondrial complexes (I-IV), suppressing glutathione antioxidant activity (Kruidering et al., 1997; Siddik, 2003), augmenting the yield of reactive oxygen species (ROS) (Arany and Safirstein, 2003) and subsequent sensitization of nociceptors and spinal dorsal horn neurons (Cavaletti et al., 2014).

Silybum marianum L. that is also known as milk thistle belongs to Carduus marianum family. Historically, it has been used for treatment of various diseases such as liver and gallbladder disorders (Karimi et al., 2011; Křen and Walterová, 2005). This plant was first introduced in Europe and was found to be useful in treatment of jaundice (Mayer et al., 2005). Silymarin, active component of Silybum marianum L. is composed of several compounds. Among them we can point to silybin $A$, silybin $B$, isosilybin $A$, isosilybin $B$, silychristin, neosilyhermin, silyhermin and silydianin (Basiglio et al., 2009; Karimi et al., 2005b; Kaur and Agarwal, 2007). Its hepatoprotective (Morishima et al., 2010), anti-cancer (Ramasamy and Agarwal, 2008), renoprotective (Karimi et al., 2005a; Shahbazi et al., 2012), immunomodulative (Gharagozloo et al., 2010) and other therapeutic effects have been proved before (Karimi et al., 2011). Beside these effects it has been known for its positive neuronal effects. Among them we can point to its neuroprotective effects in ischemia (Hirayama et al., 2016), epilepsy (Sedaghat et al., 2017), dementia (El-Marasy et al., 2018), parkinson's disease (Baluchnejadmojarad et al., 2010b; Haddadi et al., 2015; Haddadi et al., 2013; Haddadi et al., 2018; Haddadi et al., 2014) depression (Karimi and Saradeghi Keisari, 2007) and prevention of diabetic neuropathy (Baluchnejadmojarad et al., 2010a).

Literature review reveals that there is a little published data over the neuroprotective effect of silymarin on $\mathrm{CIH}$. Thereby, this study was conducted to investigate the attenuating effects of silymarin on $\mathrm{CIH}$ and to assess involvement of oxidative stress biomarkers in the observed effects.

\section{Materials and methods}

\section{Chemicals}

All chemicals were purchased from Sigma Chemical Co. (Germany). Silymarin was donated by Goldaru Pharmaceutical Company (Esfahan, Iran). Drugs solutions were prepared freshly on the days of experiment by dissolving in physiological saline $(0.9 \%$ $\mathrm{NaCl}$ ) except for silymarin which was dissolved in 50\% polyethylene glycol 400 (PEG). The drugs were given intraperitoneally (IP) on days of experimentation.

\section{Animals}

The study was carried on 56 male Wistar rats weighing 180-200g. The rats were allocated randomly in seven equal groups and housed in standard Plexiglass cages (4 rats per cage $)$ at room temperature $\left(22 \pm 3^{\circ} \mathrm{C}\right)$ and a 12 -h light period. The study was carried out in conformity with the ethical guidelines of regional research ethic committee of Tabriz University of Medical Sciences (TBZMED.REC.1394.1056).

\section{Induction of hyperalgesia}

In order to induce hyperalgesia, single dose of cisplatin $(1 \mathrm{mg} / \mathrm{kg}$, IP) was injected to the rats and then pain latency time was assessed on days 1 (30 min after cisplatin injection), 5, 10 and 15 by utilizing the tailflick test until significant hyperalgesia was detected.

\section{Tail-flick test}

The tail-flick method was utilized for quantifying pain feeling 30 minutes after drugs administration. Briefly, heat-producing beam was operated to the distal $3 \mathrm{~cm}$ of the tail by using a tail-flick apparatus (Mod.37360, UGO BASILE, Italy) with an irradiation intensity of $20 \mathrm{~mW} / \mathrm{cm}^{2}$. In order to avoid further tissue damage twenty seconds was considered as a test cutoff time. The latency time for withdrawal of the tail from the painful heat-producing beam was recorded on days 1, 5, 10 and 15.

\section{Sample preparation}

At the end of behavioral pain study (day 15), blood samples ( $\mathrm{n}=8$ per group) was collected rapidly from the carotid arteries and then centrifuged at 3500rpm for $10 \mathrm{~min}$. The serum and heparinized whole blood samples 
were collected and stored at $-80^{\circ} \mathrm{C}$ until biochemical estimation.

\section{Malondialdehyde (MDA) assay}

The amount of MDA as a major end product of oxidative damage was measured by double heating method. Briefly, serum samples were mixed with trichloroacetic acid to precipitate protein, followed by centrifuging and collecting the supernatant. The supernatant reacted with an equal volume of thiobarbitoric acid in 90- $100^{\circ} \mathrm{C}$ for $10 \mathrm{~min}$. The absorbance was measured spectrophotometrically at $532 \mathrm{~nm}$ and MDA level was reported as $\mathrm{nMol} / \mathrm{ml}$.

\section{Glutathione peroxidase (GPx) assays}

The GPx activity in heparinized whole blood samples was scaled according to instructions of commercially available GPx kit (Ransel, Randox laboratory, UK). The GPx activity was quantified at $340 \mathrm{~nm}$ and expressed as Unit/g hemoglobin. The method was first introduced by Paglia and Valentine (1967). During the procedure, GPx catalyzes the oxidation of glutathione by cumene hydroperoxide. Glutathione Reductase and NADPH help the oxidized glutathione to be rapidly transformed into the reduced form. By measuring the absorbance, the amounts of the products (resulting from the reactions) and consequently GPx would be estimated.

\section{Superoxide dismutase (SOD) assay}

Activity of SOD was estimated in heparinized whole blood samples as described by commercially available SOD kit (Ransod, Randox laboratory, UK). Intensity of the color was quantified spectrophometrically at $505 \mathrm{~nm}$. The data of SOD estimation were shown as Unit/g hemoglobin. In this method, xanthine and xanthine oxidase are used for generating superoxide radicals. Reaction between the radicals and 2-(4-iodophenyl)-3-(4nitrophenol)-5-phenyltetrazolium chloride results in the formation of red formazan dye. The higher the activity of SOD, the less red formazan is formed (Woolliams et al., 1983; Suttle, 1986; Suttle and McMurray, 1983; Arthur and Boyne, 1985).

\section{Total antioxidant status (TAS) assay}

The TAS measurement was performed according to instructions of TAS kit (Randox laboratory, UK).
Absorbance was measured by spectrophotometer at $600 \mathrm{~nm}$ and TAS results were expressed as $\mathrm{mMol} / \mathrm{l}$. In this method, metmyoglobin and $\mathrm{H} 2 \mathrm{O} 2$ turn ABTS $^{\circledR}$ (2,2'-Azino-di-[3-ethylbenzthiazoline sulphonate]) to its radical cation form which is blue-green in color. Endogenous and exogenous antioxidants would attenuate this color formation depending on their concentrations and the extent of this attenuation would be a criterion for evaluating their antioxidant capacity (Miller et al., 1993).

\section{Data analysis}

Statistical analysis was performed using SPSS software (version 16). The results were shown as mean \pm SEM values and compared by one-way analysis of variance. Significant difference was considered at the level of $P<0.05$. Tukey multiple comparison test was used to find means that are significantly different from each other.

\section{Results}

\section{Effect of cisplatin on pain threshold}

In three groups of normal, saline $(1 \mathrm{ml} / \mathrm{kg}$, IP) and cisplatin-treated $(1 \mathrm{mg} / \mathrm{kg}, \mathrm{IP})$ animals, response to the noxious stimulus was assessed on days 1 (30min after drugs administration), 5, 10 and 15 by using tail flick apparatus. Results showed that cisplatin induced significant $(P<0.05)$ pain on days 5, 10 and 15 (Figure 1).

\section{Effect of silymarin on $\mathrm{CIH}$}

Tail flick latency time was assessed in normal, vehicle (50\% PEG 400, 1ml/kg, IP), cisplatin (1 mg/kg, IP) and three cisplatin+sliymarin $(25,50$ and $100 \mathrm{mg} / \mathrm{kg}$, IP) coadministered groups. As it has been shown in Figure 2, in those groups of rats that were co-treated with cisplatin and silymarin there was a significant $(P<0.05$ and 0.01$)$ increase in pain latency time on days 10 and 15 , when compared with cisplatin received rats. The greatest effect was observed with $100 \mathrm{mg} / \mathrm{kg}$ silymarin $(P<0.01)$.

\section{Assessment of oxidative stress parameters}

At the end of pain study, the MDA, GPx, SOD and TAS as oxidative stress parameters were assessed in normal, cisplatin and cisplatin+silymarin $(100 \mathrm{mg} / \mathrm{kg})$ co-treated rats (Figure 3). In cisplatin treated rats the amount of MDA was increased $(P<0.05)$ in comparison to normal animals; while we observed a significant decrease 


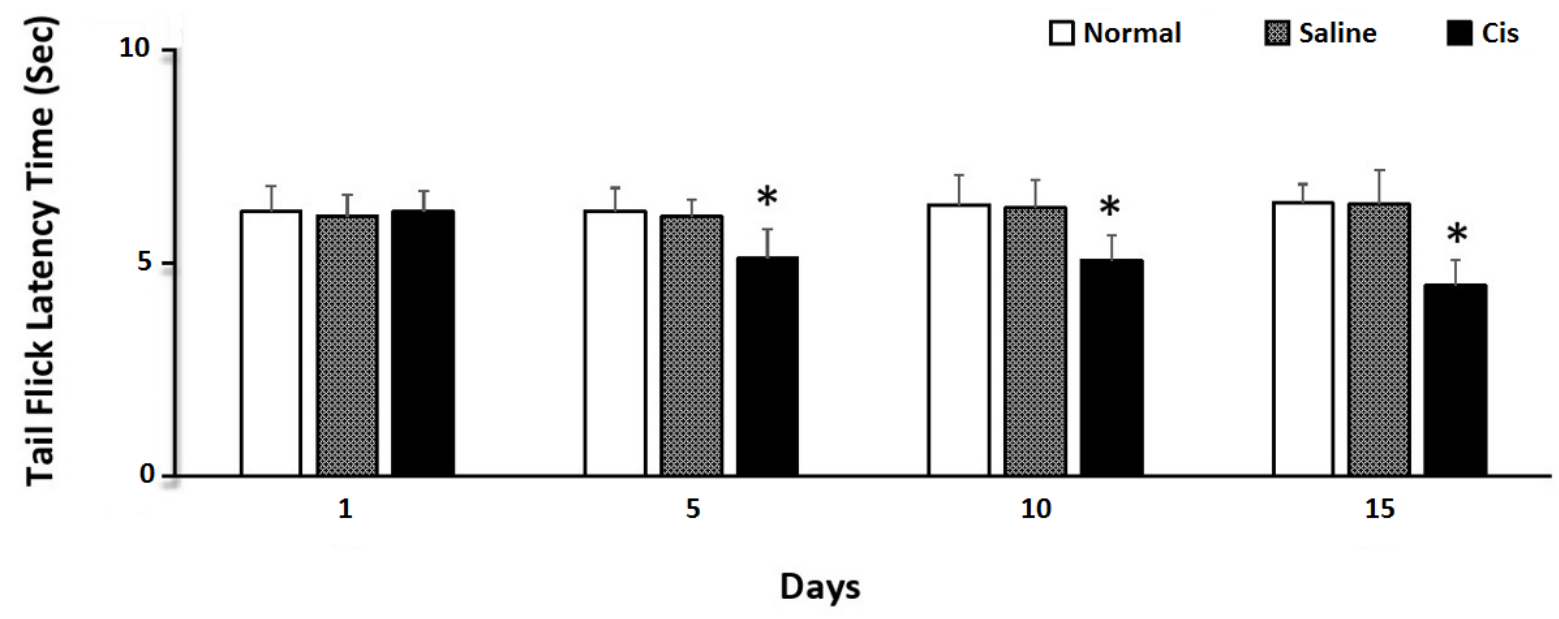

FIGURE 1. Effect of cisplatin (Cis, $1 \mathrm{mg} / \mathrm{kg}$, IP) on tail-flick latency time (s). Data has been shown as mean $\pm \mathrm{SEM}, \mathrm{n}=8$ rats per group. ${ }^{*} P<0.05$, when compared with normal group.

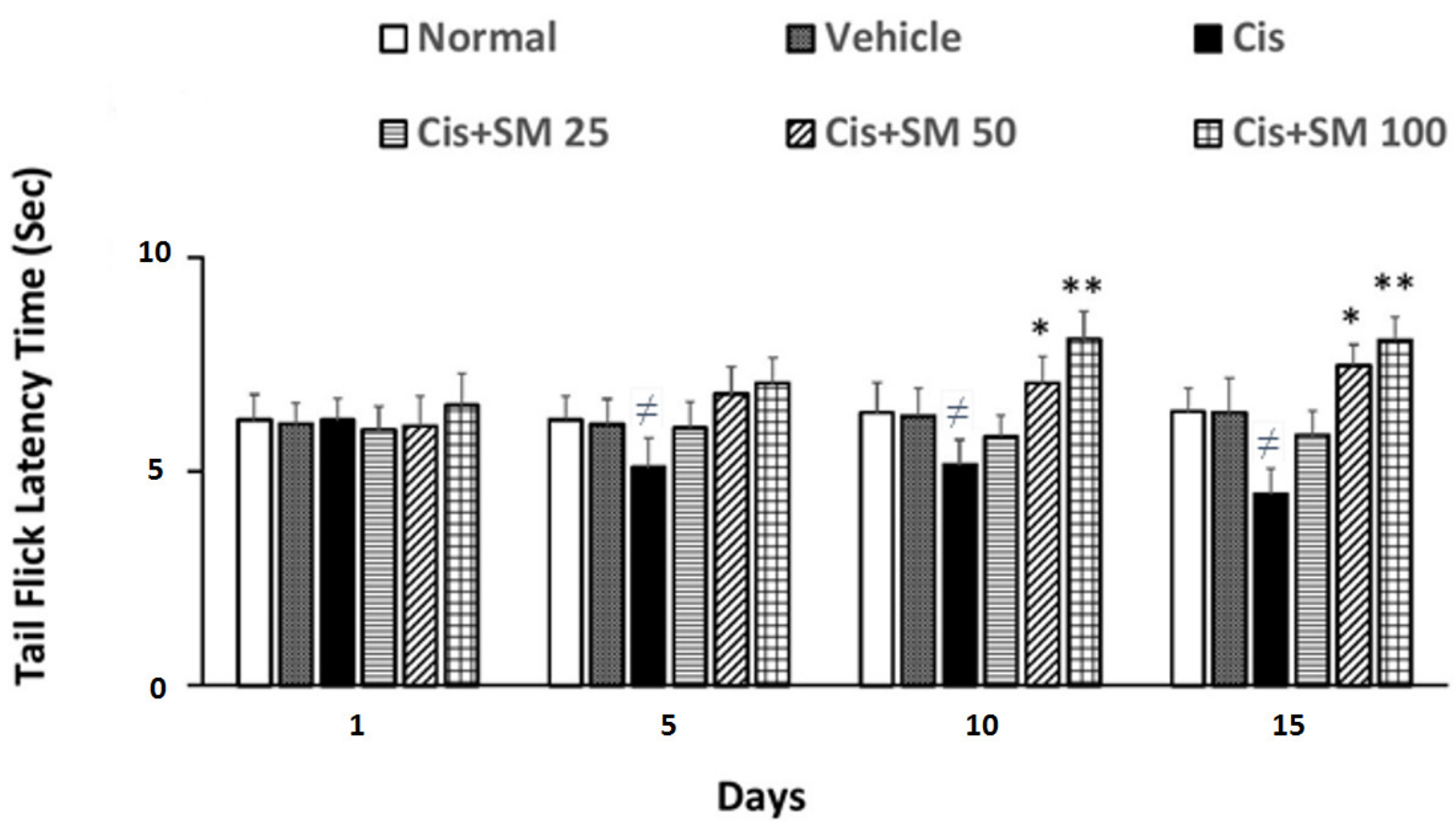

FIGURE 2. Effect of silymarin (SM, 25, 50 and $100 \mathrm{mg} / \mathrm{kg}$, IP) on cisplatin (Cis, $1 \mathrm{mg} / \mathrm{kg}$, IP)-induced hyperalgesia. Data has been shown as mean \pm SEM, $n=8$ rats per group. ${ }^{\neq} P<0.05$ when compared with normal group; ${ }^{*} P<0.05$ and ${ }^{* *} P<0.01$, when compared with Cis group.

$(P<0.01)$ in MDA level in cisplatin and silymarin coadministered animals. Furthermore, as shown in Figure 3 , cisplatin significantly reduced GPx, SOD and TAS compared to control group $(P<0.05)$; while silymarin was able to reverse all these alterations $(P<0.01)$.

\section{Discussion}

In cancer therapy, most of the cytotoxic drugs are capable to induce peripheral nervous system toxicity and painful neuropathy as an unwanted affect (Paice, 2003). Cisplatin is one of the commonly used anticancer drugs that causes peripheral neuropathic pain in a dose- and time-dependent manner (Joseph and Levine, 2009). The pain develops during 4 months and spontaneous attenuation occurs after a while, nevertheless it does not disappear completely after cessation of treatment (Authier et al., 2000). Results of an animal study revealed that mechanical allodynia and hyperalgesia last for 15 days after cisplatin injection (Pacharinsak and Beitz, 2008). In our study, cisplatin $(1 \mathrm{mg} / \mathrm{kg})$ caused remarkable hypersensitivity to thermal stimulus on days 5, 10 and 15. Afterward, this dose of cisplatin was used for producing hyperalgesia throughout the study. Cisplatin was administered in a single dose and 

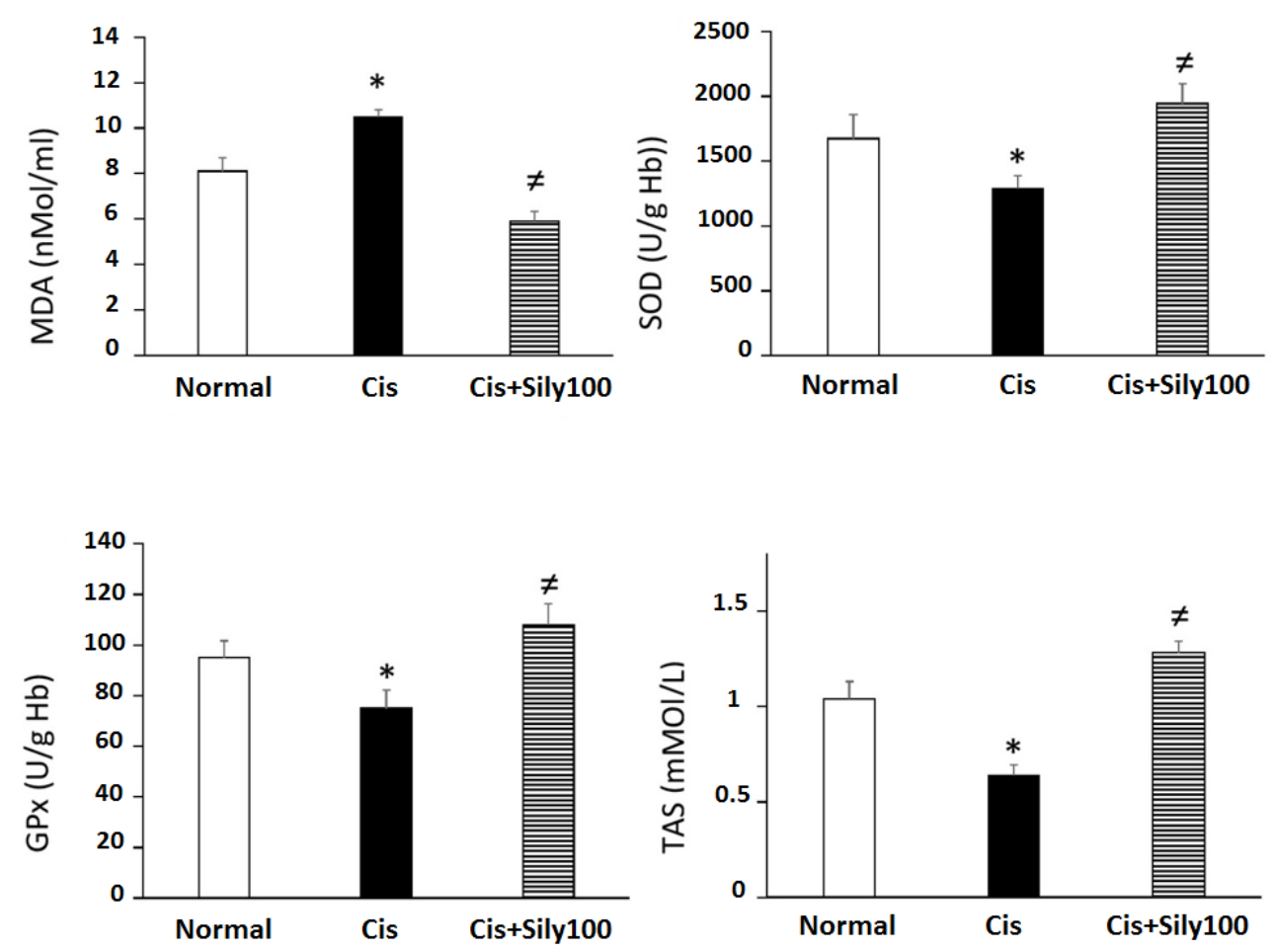

FIGURE 3. The levels of malondialdehyde (MDA, upper left), superoxide dismutase (SOD, upper right), glutathione peroxidase (GPx, lower left) and total antioxidant status (TAS, lower right) in normal, cisplatin (Cis, $1 \mathrm{mg} / \mathrm{kg}$, IP), cisplatin and silymarin (SM, 100mg/kg/day, IP) co-treated rats. Data has been shown as mean \pm SEM, $\mathrm{n}=8$ rats per group. ${ }^{*} P<0.05$, when compared with normal group; ${ }^{\ddagger} P<0.01$, when compared with Cis group.

decreased the pain threshold in the animals over time so that they would react to tail-flick test faster than normal animals. The mean latency time was lowered day by day, so the most prominent decrease was observed on day fifteen. This observation is in accordance with previous studies showing CIH (Balayssac et al., 2009; Nayebi et al., 2012).

Oxidative stress reactions are among underlying mechanisms of $\mathrm{CIH}$. Free radicals such as superoxide, hydroxyl, hydrogen peroxide and other radicals produced by lipid peroxidation can exacerbate oxidative stress reactions, nerve tissue damages and as a result, could cause hyperalgesia (Kittur et al., 2002; NamvaranAbbas-Abad and Tavakkoli, 2012). Therefore, the use of naturally occurring antioxidant compounds for attenuating cisplatin-induced neuropathic pain would be justifiable.

In recent years, lots of studies have been focused on the concept of pain (Luo et al., 2020; Parvizpur et al., 2020; Majidi et al., 2018). In this study, a natural compound which is extracted from an herb was evaluated. Silymarin is a natural extract of Silybum marianum containing several flavonolignans such as silybin A, silybin B, isosilybin A, isosilybin $\mathrm{B}$, silychristin and silydianin
(Surai, 2015). For its antioxidant activity, we can refer to increase of cellular glutathione, superoxide dismutase, glutathione peroxidase and catalase in rat brain (Manna et al., 1999). In our study, silymarin decreased CIH dose dependently so the most prominent effect was obtained at dose of $100 \mathrm{mg}$ on day fifteen. Previous in vivo studies have proved the antinociceptive effects of silymarin and suggested its anti-inflammatory and antioxidant properties as the underlying mechanisms. Silymarin-induced inhibition of ROS and inflammatory mediators were noted in some studies (Hassani et al., 2015; Jadhav and Upasani, 2009; Sahib, 2011). In our study estimation of oxidative stress parameters indicates a significant increase and decrease in antioxidant (SOD, GPx and TAS levels) and oxidative (MDA) parameters activity respectively in cisplatin and silymarin co-treated group on day fifteen. It seems that effect of silymarin on improving of $\mathrm{CIH}$ may be related to its potential antioxidant activity. It has been shown that the analgesic effects of antioxidant compounds like silymarin in the pain thermal test can be due to their inhibitory effect on the 2-lipoxygenase enzyme (Hunt et al., 2001; VargasMendoza et al., 2014). Thus suppression of inflammatory mediators subsequent to silymarin antioxidant activity is 
not negligible.

\section{Conclusion}

According to our results, we suggested that silymarin may be useful in attenuating of $\mathrm{CIH}$ possibly through improving stress oxidative biomarkers. However, further investigations should be performed to explain its exact mechanism of action and efficacy in treating $\mathrm{CIH}$.

\section{Acknowledgments}

We wish to thank the director of the Drug Applied Research Center of the Tabriz University of Medical Sciences for supporting this study (No.: 5-149929).

\section{Conflict of interest}

The authors declared no conflict of interest for this study.

\section{References}

Arany I, Safirstein R L. Cisplatin nephrotoxicity. Semin Nephrol 2003; 23: 460-464. https://doi.org/10.1016/S02709295(03)00089-5

Areti A, Yerra V, Naidu VG, Kumar A. Oxidative stress and nerve damage: role in chemotherapy induced peripheral neuropathy. Redox Biol 2014; 2: 289-95. https://doi. org/10.1016/j.redox.2014.01.006

Arthur JR, Boyne R. Superoxide dismutase and glutathione peroxidase activities in neutrophils from selenium deficient and copper deficient cattle. Life Sci 1985; 36: 1569-75. https://doi.org/10.1016/0024-3205(85)90381-9

Authier N, Fialip J, Eschalier A, Coudoré F. Assessment of allodynia and hyperalgesia after cisplatin administration to rats. Neurosci Lett 2000; 291: 73-6. https://doi.org/10.1016/ S0304-3940(00)01373-2

Balayssac D, Cayre A, Ling B, Maublant J, Penault-Llorca F, Eschalier A, et al. Increase in morphine antinociceptive activity by a P-glycoprotein inhibitor in cisplatin-induced neuropathy. Neurosci Lett 2009; 465: 108-12. https://doi. org/10.1016/j.neulet.2009.09.003

Baluchnejadmojarad T, Roghani M, Khastehkhodaie Z. Chronic treatment of silymarin improves hyperalgesia and motor nerve conduction velocity in diabetic neuropathic rat. Phytother Res 2010a; 24: 1120-5. https://doi.org/10.1002/ ptr.3078

Baluchnejadmojarad T, Roghani M, Mafakheri M. Neuroprotective effect of silymarin in 6-hydroxydopamine hemi-parkinsonian rat: involvement of estrogen receptors and oxidative stress. Neurosci Lett 2010b; 480: 206-10. https://doi.org/10.1016/j.neulet.2010.06.038

Basiglio CL, Pozzi EJ, Mottino AD, Roma MG. Differential effects of silymarin and its active component silibinin on plasma membrane stability and hepatocellular lysis. Chem Biol Interact 2009; 179: 297-303. https://doi.org/10.1016/j. cbi.2008.12.008

Cavaletti G, Ceresa C, Nicolini G, Marmiroli P. Neuronal drug transporters in platinum drugs-induced peripheral neurotoxicity. Anticancer Res 2014; 34: 483-6.

Dzagnidze A, Katsarava Z, Makhalova J, Liedert B, Yoon MS, Kaube H, et al. Repair capacity for platinum-DNA adducts determines the severity of cisplatin-induced peripheral neuropathy. J Neurosci 2007; 27: 9451-7. https:// doi.org/10.1523/JNEUROSCI.0523-07.2007

El-Marasy SA, Abd-Elsalam RM, Ahmed-Farid OA. Ameliorative effect of silymarin on scopolamine-induced dementia in rats. Open Access Maced J Med Sci 2018; 6: 1215. https://doi.org/10.3889/oamjms.2018.257

Gharagozloo M, Velardi E, Bruscoli S, Agostini M, Di Sante M, Donato V, et al. Silymarin suppress CD4+ T cell activation and proliferation: effects on NF- $\mathrm{BB}$ activity and IL-2 production. Pharmacol Res 2010; 61: 405-9. https:// doi.org/10.1016/j.phrs.2009.12.017

Gill JS, Windebank AJ. Cisplatin-induced apoptosis in rat dorsal root ganglion neurons is associated with attempted entry into the cell cycle. J Clin Investig 1998; 101: 2842-50. https://doi.org/10.1172/JCI1130

Majidi Z, Fekri K, Delazar A, Vaez H. Evaluation of the effect of aerial parts of Scrophularia atropatana grossh total extracts on analgesic activity and morphine induced tolerance in mice. Pharm Sci 2018; 24: 112-7. https://doi. org/10.15171/PS.2018.17

Haddadi R, Brooshghalan SE, Farajniya S, Nayebi AM, Sharifi H. Short-term treatment with silymarin improved 6-OHDA-induced catalepsy and motor imbalance in hemiParkisonian rats. Adv Pharm Bull 2015; 5: 463. https://doi. org/10.15171/apb.2015.063

Haddadi R, Nayebi AM, Brooshghalan SE. Pre-treatment with silymarin reduces brain myeloperoxidase activity and inflammatory cytokines in 6-OHDA hemi-parkinsonian rats. Neurosci Lett 2013; 555: 106-11. https://doi.org/10.1016/j. neulet.2013.09.022

Haddadi R, Nayebi AM, Brooshghalan SE. Silymarin prevents apoptosis through inhibiting the Bax/caspase-3 expression and suppresses toll like receptor-4 pathway in the SNc of 6-OHDA intoxicated rats. Biomed Pharmacother 2018; 104: 
127-36. https://doi.org/10.1016/j.biopha.2018.05.020

Haddadi R, Nayebi AM, Farajniya S, Brooshghalan SE, Sharifi H. Silymarin improved 6-OHDA-induced motor impairment in hemi-parkisonian rats: behavioral and molecular study. DARU J Pharm Sci 2014; 22: 1-9. https:// doi.org/10.1186/2008-2231-22-38

Hassani FV, Rezaee R, Sazegara H, Hashemzaei M, Shirani K, Karimi G. Effects of silymarin on neuropathic pain and formalin-induced nociception in mice. Iran J Basic Med Sci 2015; 18: 715 .

Hirayama K, Oshima H, Yamashita A, Sakatani K, Yoshino A, Katayama Y. Neuroprotective effects of silymarin on ischemia-induced delayed neuronal cell death in rat hippocampus. Brain Res 2016; 1646: 297-303. https://doi. org/10.1016/j.brainres.2016.06.018

Hunt EJ, Lester CE, Lester EA, Tackett RL. Effect of St. John's wort on free radical production. Life Scie 2001; 69: 181-90. https://doi.org/10.1016/S0024-3205(01)01102-X

Jadhav G, Upasani C. Analgesic effect of silymarin in experimental induced pain in animal models. J Pharm Res 2009; 2: 1276-8.

Joseph EK, Levine JD. Comparison of oxaliplatin-and cisplatin-induced painful peripheral neuropathy in the rat. J Pain 2009; 10: 534-41. https://doi.org/10.1016/j. jpain.2008.12.003

Karimi GH, Fallah Huseini H, Ramezani M, Tahoonian Z. Protective effect of silybum marianum (1.) gaertn. seeds extract and silymarin against cisplatin-induced acute nephrotoxicity in rats. J Med Plants 2005a; 1: 42-5.

Karimi G, Ramezani M, Tahoonian Z. Cisplatin nephrotoxicity and protection by milk thistle extract in rats. Evid Based Compl Alt Med 2005b; 2: 383-6. https://oi.org/10.1093/ ecam/neh103

Karimi G, Saradeghi Keisari M. Evaluation of antidepressant effect of ethanolic and aqueous extracts of Silybum marianum L. seed in mice. J Med Plants 2007; 6: 3843.

Karimi G, Vahabzadeh M, Lari P, Rashedinia M, Moshiri M. "Silymarin", a promising pharmacological agent for treatment of diseases. Iran J Basic Med Sci 2011; 14: 308 .

Kaur M, Agarwal R. Silymarin and epithelial cancer chemoprevention: how close we are to bedside? Toxicol Appl Pharmacol 2007; 224: 350-9. https://doi.org/10.1016/j. taap.2006.11.011

Khasabova IA, Khasabov SG, Olson JK, Uhelski ML, Kim AH, Albino-Ramírez AM, et al. Pioglitazone, a PPAR $\gamma$ agonist, reduces cisplatin-evoked neuropathic pain by protecting against oxidative stress. Pain 2019; 160: 688-701. https://doi.org/10.1097/j.pain.0000000000001448

Kim HJ, Lee JH, Kim SJ, Oh GS, Moon HD, Kwon KB, et al. Roles of NADPH oxidases in cisplatin-induced reactive oxygen species generation and ototoxicity. J Neurosci 2010; 30: 3933-46. https://doi.org/10.1523/ JNEUROSCI.6054-09.2010

Kittur S, Wilasrusmee S, Pedersen WA, Mattson MP, Straube-West K, Wilasrusmee C, et al. Neurotrophic and neuroprotective effects of milk thistle (Silybum marianum) on neurons in culture. J Mol Neurosci 2002; 18: 265-9. https://doi.org/10.1385/JMN:18:3:265

Křen V, Walterová D. Silybin and silymarin-new effects and applications. Biomed Pap 2005; 149: 29-41. https://doi. org/10.5507/bp.2005.002

Kruidering M, Van De Water B, De Heer E, Mulder GJ, Nagelkerke JF. Cisplatin-induced nephrotoxicity in porcine proximal tubular cells: mitochondrial dysfunction by inhibition of complexes I to IV of the respiratory chain. J Pharmacol Exp Ther 1997; 280: 638-49.

Lee JH, Chae JW, Kim JK, Kim HJ, Chung JY, Kim YH. Inhibition of cisplatin-resistance by RNA interference targeting metallothionein using reducible oligo-peptoplex. J Control Release 2015; 215: 82-90. https://doi.org/10.1016/j. jconrel.2015.07.015

Luo Y, Wang CZ, Sawadogo R, Tan T, Yuan CS. Effects of Herbal Medicines on Pain Management. Am J Chinese Med 2020; 48: 1-6. https://doi.org/10.1142/ S0192415X20500019

Lomeli N, Di K, Czerniawski J, Guzowski JF, Bota DA. Cisplatin-induced mitochondrial dysfunction is associated with impaired cognitive function in rats. Free Radic Biol Med 2017; 102: 274-86. https://doi.org/10.1016/j. freeradbiomed.2016.11.046

Manna SK, Mukhopadhyay A, Van NT, Aggarwal BB. Silymarin suppresses TNF-induced activation of NF- $\kappa B$, c-Jun N-terminal kinase, and apoptosis. J Immunol 1999; 163: 6800-9.

Mayer KE, Myers RP, Lee SS. Silymarin treatment of viral hepatitis: a systematic review. JViral Hepat 2005; 12: 559-67. https://doi.org/10.1111/j.1365-2893.2005.00636.x

Miller NJ, Rice-Evans C, Davies MJ, Gopinathan V, Milner A. A novel method for measuring antioxidant capacity and its application to monitoring the antioxidant status in premature neonates. Clin Sci 1993; 84: 407-12. https://doi. org/10.1042/cs0840407 
Morishima C, Shuhart MC, Wang CC, Paschal DM, Apodaca MC, Liu Y, et al. Silymarin inhibits in vitro T-cell proliferation and cytokine production in hepatitis $\mathrm{C}$ virus infection. Gastroenterology 2010; 138: 671-81. https://doi. org/10.1053/j.gastro.2009.09.021

Namvaran-Abbas-Abad A, Tavakkoli F. Antinociceptive effect of salvia extract on cisplatin-induced hyperalgesia in mice. Neurophysiology 2012; 43: 452-8. https://doi. org/10.1007/s11062-012-9249-1

Nayebi AM, Sharifi H, Ramadzani M, Rezazadeh H. Effect of acute and chronic administration of carbamazepine on Cisplatin-induced hyperalgesia in rats. Jundishapur J Nat Pharm Prod 2012; 7: 27. https://doi.org/10.17795/ jjnpp-3559

Pacharinsak C, Beitz A. Animal models of cancer pain. Comp Med 2008; 58: 220-33.

Paglia DE, Valentine WN. Studies on the quantitative and qualitative characterization of erythrocyte glutathione peroxidase. J Lab Clin Med 1967; 70: 158-69

Paice J A. Mechanisms and management of neuropathic pain in cancer. J Support Oncology 2003; 1: 107-120.

Parvizpur A, Fekri K, Fekri L, Ghadimi P, Charkhpour M. The role of duloxetine in changing the process of tolerance to morphine analgesic effects in male rats. J Rep Pharma Sci 2020; 9: 215. https://doi.org/10.4103/jrptps. JRPTPS 8719

Podratz JL, Knight AM, Ta LE, Staff NP, Gass JM, Genelin $\mathrm{K}$, et al. Cisplatin induced mitochondrial DNA damage in dorsal root ganglion neurons. Neurobiol Dis 2011; 41: 6618. https://doi.org/10.1016/j.nbd.2010.11.017

Ramasamy K, Agarwal R. Multitargeted therapy of cancer by silymarin. Cancer Lett 2008; 269: 352-62. https://doi. org/10.1016/j.canlet.2008.03.053

Sahib AS. Antinociceptive effect of silymarin in experimental animal. Al-Kindy College Medical Journal 2011; 7: 91-4.

Sedaghat R, Zarrinkhameh Z, Afshin-Majd S, Ansari F, Sharayeli M, Roghani M. The effect of silymarin on prevention of hippocampus neuronal damage in rats with temporal lob epilepsy. J Basic Clin Pathophysiol 2017; 5: 45-50.

Shahbazi F, Dashti-Khavidaki S, Khalili H, Lessan-Pezeshki M. Potential renoprotective effects of silymarin against nephrotoxic drugs: a review of literature. J Pharm Pharm Sci 2012; 15: 112-23. https://doi.org/10.18433/J3F88S

Siddik ZH. Cisplatin: mode of cytotoxic action and molecular basis of resistance. Oncogene 2003; 22: 7265-79. https:// doi.org/10.1038/sj.onc.1206933

Surai PF. Silymarin as a natural antioxidant: an overview of the current evidence and perspectives. Antioxidants 2015; 4: 204-47. https://doi.org/10.3390/antiox4010204

Suttle NF. Copper deficiency in ruminants; recent developments. Vet Rec 1986; 119: 519-22. https://doi. org/10.1136/vr.119.21.519

Suttle NF, McMurray $\mathrm{CH}$. Use of erythrocyte copper: zinc superoxide dismutase activity and hair or fleece copper concentrations in the diagnosis of hypocuprosis in ruminants. Res Vet Sci1983; 35: 47-52. https://oi. org/10.1016/S0034-5288(18)32201-X

Ta LE, Espeset L, Podratz J, Windebank AJ. Neurotoxicity of oxaliplatin and cisplatin for dorsal root ganglion neurons correlates with platinum-DNA binding. Neurotoxicology 2006; 27: 992-1002. https://doi.org/10.1016/j. neuro.2006.04.010

Todd RC, Lippard SJ. Inhibition of transcription by platinum antitumor compounds. Metallomics 2009; 1: 280-291. https://doi.org/10.1039/b907567d

Vargas-Mendoza N, Madrigal-Santillán E, Morales-González Á, Esquivel-Soto J, Esquivel-Chirino C, y GonzálezRubio MG, et al. Hepatoprotective effect of silymarin. World J Hepatol 2014; 6: 144. https://doi.org/10.4254/wjh. v6.i3.144

Woolliams JA, Woolliams G, Anderson PH, McMurray $\mathrm{CH}$. Variation in the activities of glutathione peroxidase and superoxide dismutase and in the concentration of copper in the blood in various breed crosses of sheep. Res Vet Sci 1983; 34: 253-6. https://doi.org/10.1016/S00345288(18)32219-7

Yang Z, Schumaker LM, Egorin MJ, Zuhowski EG, Guo Z, Cullen KJ. Cisplatin preferentially binds mitochondrial DNA and voltage-dependent anion channel protein in the mitochondrial membrane of head and neck squamous cell carcinoma: possible role in apoptosis. Clin Cancer Res 2006; 12: 5817-25. https://doi.org/10.1158/1078-0432. CCR-06-1037 